\title{
Experimental and numerical investigation of the weld geometry effects on Type IV cracking behaviour in $\mathbf{P 9 1}$ steel
}

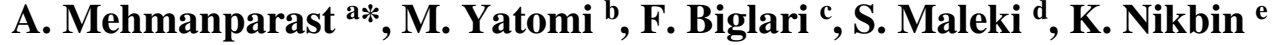 \\ a Offshore Renewable Energy Engineering Centre, Cranfield University, College Road, Cranfield, MK43 0AL, UK \\ ${ }^{\mathrm{b}}$ Research Laboratory, IHI Corporation, 1 Shin-nakahara-cho, Isogo-ku, Yokohama 235-8501, Japan \\ ${ }^{c}$ Mechanical Engineering Department, Amirkabir University of Technology, Iran \\ d TWI Ltd. Granta Park, Great Abington, Cambridge CB21 6AL, UK \\ ${ }^{\text {e }}$ Department of Mechanical Engineering, Imperial College London, London, SW7 2AZ. UK. \\ *Corresponding author: a.mehmanparast@cranfield.ac.uk
}

\begin{abstract}
The focus of the present study is on creep crack growth behaviour in Type IV region of P91 steel weldments at $650{ }^{\circ} \mathrm{C}$. In the experimental studies on small and large-scale single-edge notched specimens in tension, SENT, the effects of weld dimensions and specimen size on the creep crack growth behaviour of the material are investigated. The experimental results demonstrate that the crack starts to propagate at an angle normal to the loading direction, subsequently deviates towards the Type IV region and eventually ruptures when the crack growth angle becomes parallel to the loading direction. The creep rupture data for SENT specimens compared well with those of the round bar specimens for P91 welded joints. In addition, the data for crack growth rates from the deviating crack path were correlated with the $C^{*}$ fracture mechanics parameter and shown to be in good agreement with standard compact tension test data. To predict the creep crack growth in the Type IV region, finite element simulations were performed in conjunction with a multiaxial ductility damage criterion at the weld/base metal interface. Given that a lower failure strain along the Type IV region is prominent, it is shown that the cracking, in line with the experiments, followed the HAZ region and led to the final creep rupture in the net section.
\end{abstract}

Keywords: Type IV cracking, creep crack growth, large-scale testing, high temperature failure, P91

\section{Introduction}

High Chromium $(\mathrm{Cr})$ ferritic heat-resistant steels are used in boiler components in ultra-super critical (USC) thermal power plants operating at above $600{ }^{\circ} \mathrm{C}$ due to their excellent creep properties. Especially, Mod. 9Cr-1Mo steel (ASME Grade. 91 steel), also known as P91 steel, is widely used in power plant components $e . g$. thick-walled pipes. In the welded joints the creep failure often occurs in the heat affected zone (HAZ) which has relatively low creep strength, compared to the base metal (BM) and the weld metal (WM). The HAZ region is narrow and sandwiched by the $\mathrm{BM}$ on one side and by the WM on the other, which leads to a constraint effect on the deformation of the HAZ and therefore Type IV cracking occurs in the HAZ region with little deformation [1][2]. In order to have an accurate estimation of the expected lifetime for a component operating at high temperatures, it is quite important to precisely characterise the creep deformation and crack growth behaviour in the welded joints to prevent catastrophic failures during operation. 
The creep rupture and/or creep crack growth (CCG) behaviour of Type IV cracking of Mod. 9Cr1 Mo steel has been explored in previous studies [3]-[9]. The existing literature data demonstrate that the creep deformation, crack initiation and crack growth behaviour in P91 welded joints are noticeably influenced by the size and geometry of the examined components. While the previous studies focused on fully penetrated welded joints, the creep deformation and crack growth behaviour in fillet welded joints and partially penetrated welded joints need to be better understood. In the case of the full penetration welded joints, the HAZ region exists along the cross section, which is almost perpendicular to the loading direction. Therefore, Type IV cracking occurs and the crack propagates along the HAZ region until final failure happens. In the components of power plant boilers operating at high temperatures, fillet welded joints or partial penetration welded joints are widely used. In such welded joints, Type IV cracking occurs at the HAZ region but this region is not always perpendicular to the principal stress direction, and depending on the weld design the angle varies between $0^{\circ}$ and $90^{\circ}$. An important area which is yet to be fully understood is the determination of the limiting angle at which creep crack growth would exhibit a deviation from a straight line to allow the cracking to occur along the HAZ region.

In this work, partially penetrated welded joints made of P91 steel which were previously tested and provisionally analysed in [10] are comprehensively analysed and compared with the existing data on other specimen geometries. Moreover, finite element simulations have been performed, in conjunction with damage modelling, to predict the crack path and crack propagation behaviour in single-edge notched specimens in tension, SENT, extracted from partially penetrated welded joints. The experimental and numerical studies in this work have been carried out to investigate the crack growth behaviour in complicated weld geometries and examine the sensitivity of the material's behaviour to the specimen size and weld dimensions. The present study provides an insight into the exploration of the crack growth direction and failure behaviour for Type IV cracking by orienting the $\mathrm{HAZ}$ region along a singled edged arc with the angle varying between $0^{\circ}$ and $90^{\circ}$, with respect to the loading direction.

\section{Specimen Preparation and Experimental Data Analysis}

\subsection{Specimen geometry and dimensions}

The material examined in this work is Mod. 9Cr-1Mo steel (ASME Grade 91 steel) the chemical composition of which was previously reported by Yatomi et al. [10]. The welded joints were fabricated using the shielded metal arc welding (SMAW) technique with post-weld heat treatment (PWHT) of $740{ }^{\circ} \mathrm{C}$ for 2.4 hours. Two large SENT specimens and one small SENT sample were extracted for the experimental programme. As shown in Figure 1 and Figure 2, the large SENT specimens were fabricated with the total length of $L=1 \mathrm{~m}$, thickness of $B=40 \mathrm{~mm}$ and width of $W$ $=60 \mathrm{~mm}$. The large SENT samples contained weld regions at the mid-length of the specimens which were $100 \mathrm{~mm}$ long with $30 \mathrm{~mm}$ (in large SENT1 as schematically shown in Figure 1) and $10 \mathrm{~mm}$ (in large SENT2 as schematically shown in Figure 2) in depth at the centre of the weld tapering down to the edges making an approximate oval shape of the weld region. In addition to large SENT specimens, a small SENT specimen was extracted from a large welded joint, with the weld depth of $10 \mathrm{~mm}$, which was previously subjected to creep loading conditions for a short while. The small SENT sample had the width of $W=30 \mathrm{~mm}$ and thickness of $B=6 \mathrm{~mm}$ in the gauge region. An electrical discharge machining (EDM) notch of $2 \mathrm{~mm}$ long was used to create a starter crack in all 
test specimens. It is worth noting that friction grips and pin loading mechanism were used for creep testing of the large and small SENT samples, respectively.

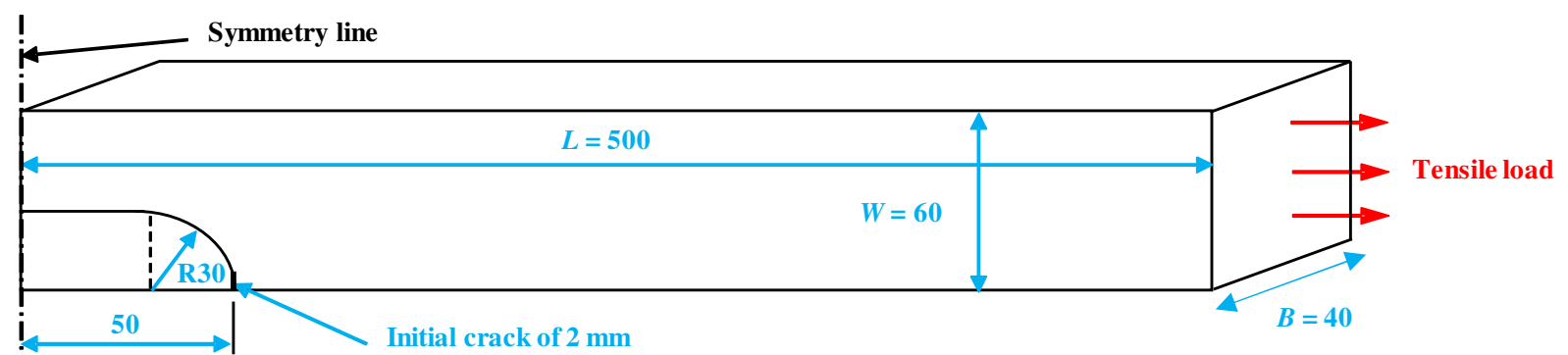

Figure 1: The dimensions of large SENT1 specimen (All dimensions are in millimetres)

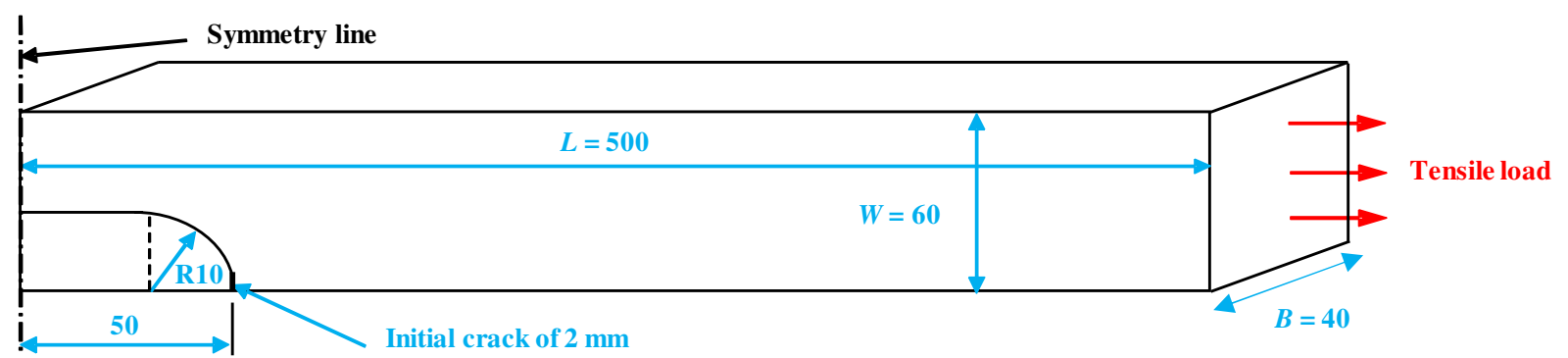

Figure 2: The dimensions of large SENT2 specimen (All dimensions are in millimetres)

\subsection{Loading conditions}

The test set-up for one of the large SENT welded specimens (i.e. large SENT2) with an overall dimensions of $40 \times 60 \times 1000 \mathrm{~mm}^{3}$ is shown in Figure 3. The blue dashed line in this figure shows the geometry of the weld in the examined test specimen. As seen in this figure, the specimens were heated up to the testing temperature using a large furnace. The creep tests on all three SENT specimens were conducted at $650{ }^{\circ} \mathrm{C}$ with an applied stress of $60 \mathrm{MPa}$ which is corresponding to $K$ $=5.16 \mathrm{MPa} \sqrt{m}$ and $K=5.06 \mathrm{MPa} \sqrt{m}$ at the beginning of the test in the large and small SENT specimens, respectively. The axial displacement in these three tests were monitored using an external capacitance gauge, machine displacement data and a Linear Variable Differential Transformer (LVDT) for large SENT1, large SENT2 and small SENT specimen, respectively. Moreover, Direct Current Potential Drop (DCPD) measurements were conducted near the starter crack tip on the large SENT1 and small SENT specimen to monitor the crack growth behaviour in these tests. As shown and provisionally discussed in the work by Yatomi et al. [10], for the given loading conditions the load-up behaviour of all three SENT specimens at $650{ }^{\circ} \mathrm{C}$ was dominantly linear, indicating elastic-creep deformation (in the absence of significant plasticity) in the examined test specimens. 


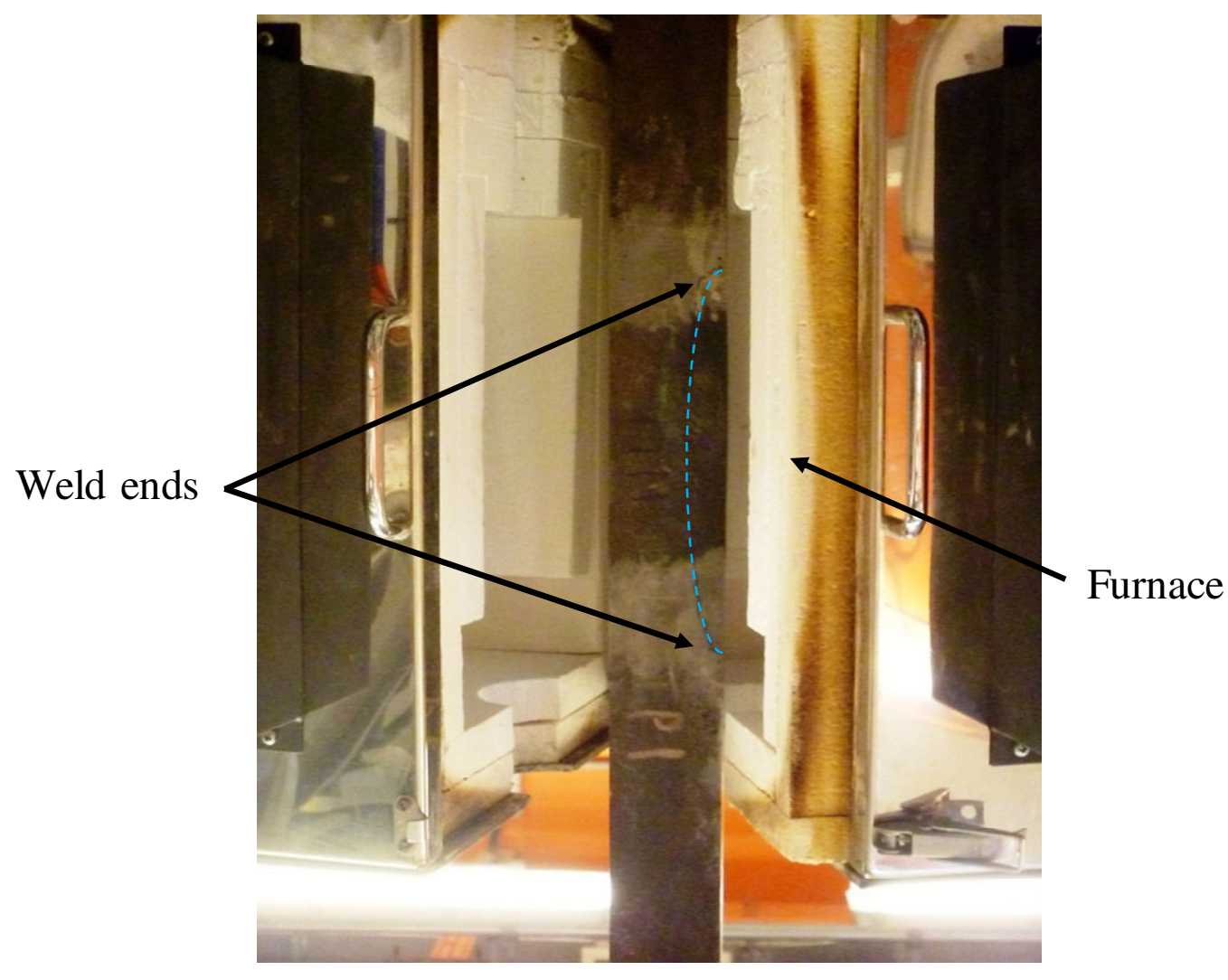

Figure 3: The test set-up for large SENT2 specimen

\subsection{Displacement and voltage trends}

The experimental displacements recorded during creep tests on two large SENT specimens and one small SENT sample are presented in Figure 4(a) and Figure 4(b), respectively [10]. Moreover, the DCPD output voltage measurements from the large SENT1 and small SENT specimen are shown in Figure 5 [10]. It can be seen in Figure 4 that while the small SENT specimen showed a continuous increase in displacement from the beginning of the test, the larger samples exhibited an increase in axial displacement only after $92 \%$ and $48 \%$ of the test duration in large SENT1 and SENT2 specimen, respectively. Figure 5 shows that an increasing trend in DCPD output voltage is observed after $92 \%$ and $45 \%$ of the test duration in large SENT1 (see Figure 5 (a)) and small SENT specimen (see Figure 5(b)), respectively. The comparison of Figure 4(a) and Figure 5(a) reveals that for the dominant majority of the test duration on large SENT1 specimen, there was no evidence of axial displacement or crack propagation, however once the crack started to propagate towards the end of the test a rapid acceleration was observed both in axial displacement and DCPD output voltage. A similar comparison between Figure 4(b) and Figure 5(b) shows that while an increase in axial displacement was observed from the beginning of the test, there was no sign of crack propagation until after around half of the test duration that the DCPD output voltage started to show a noticeable increasing trend. 


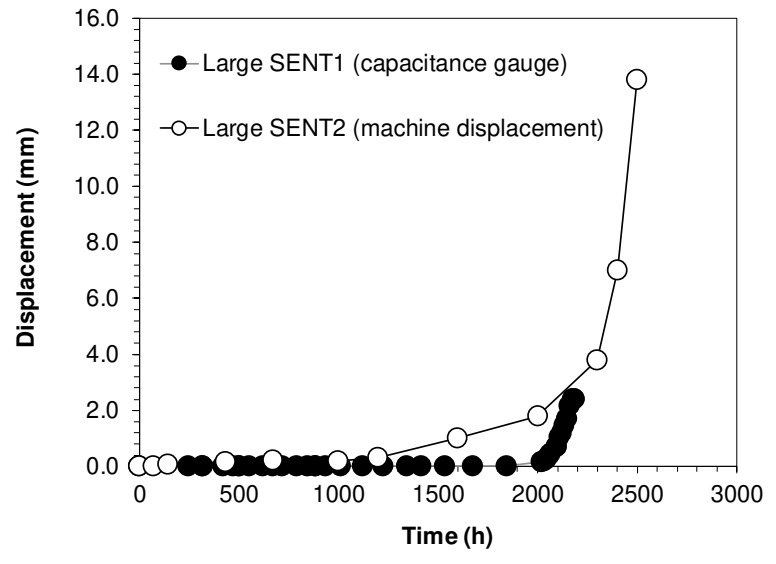

(a)

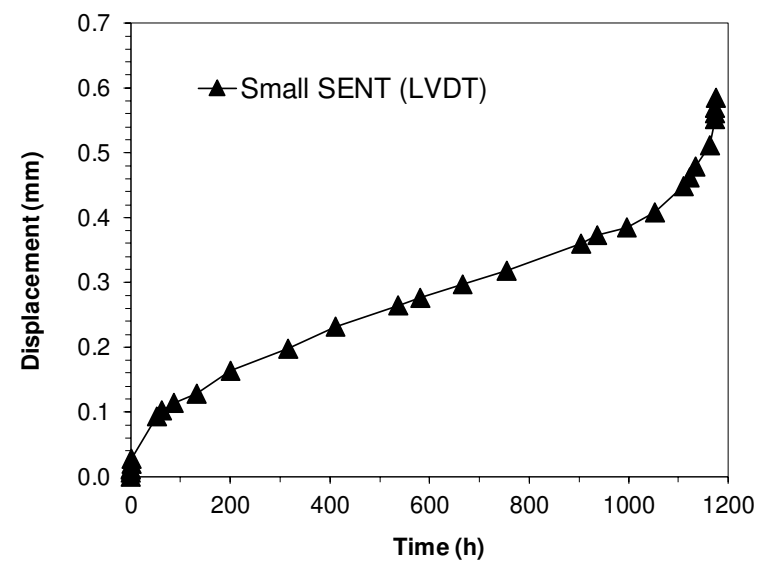

(b)

Figure 4: Displacement variations during creep tests on: (a) large SENT specimens, (b) small SENT specimen (taken from [10])

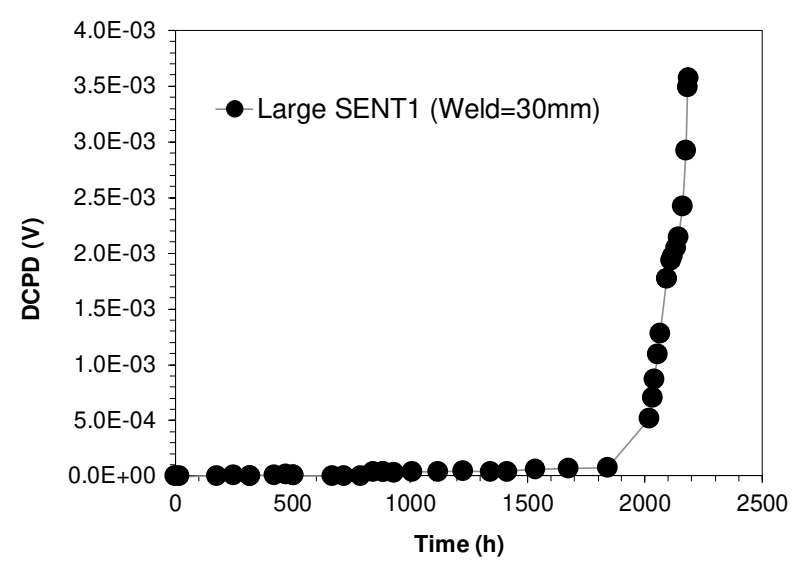

(a)

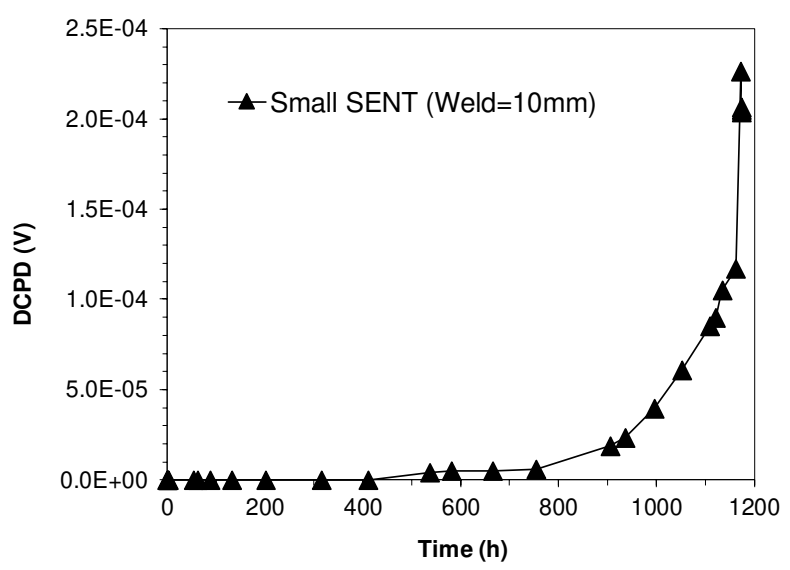

(b)

Figure 5: DCPD output voltage variations during creep tests on: (a) large SENT1 specimen, (b) small SENT specimen (taken from [10])

\subsection{Creep crack growth analysis}

Following the guidelines provided in [11]-[14], the crack growth data obtained from SENT specimens were analysed and the CCG rate, $d a / d t$, correlation with the $C^{*}$ fracture mechanics parameter was presented and discussed in the previous work by Yatomi et al. [10]. As discussed in [10], the results from large SENT samples exhibited an almost linear trend in $d a / d t v s . C^{*}$ plot, with the data points falling upon the upper bound of the data set obtained from P91 welded compact tension, $\mathrm{C}(\mathrm{T})$, specimens tested at $600-650{ }^{\circ} \mathrm{C}$ [5], [15]. However, towards the end of the test the CCG rate dropped and stayed constants while the $C^{*}$ value was increasing. This change in the CCG behaviour is thought to be due to the deviation of the crack path from the HAZ region and propagation into the BM which had led to a lower, and relatively constant, CCG rate while the sample was creeping and the increase in elongation was causing an increase in the calculated $C^{*}$ value. This implies that the crack path has a significant impact on the crack growth behaviour of the 
material, hence there is need to analyse the deviation in crack growth direction by means of finite element modelling.

\subsection{Creep rupture analysis}

The rupture times for large SENT1 and SENT2 specimens were 2,185 hours and 2,505 hours, respectively. The rupture time for small SENT specimen was 1,173 hours. One of the ways to estimate the rupture life of a component containing initial defects or cracks is to use the rupture data of round bar specimens. In the current study, the long-term creep rupture data for the BM and welded joints of P91 steel reported in the literature [16] have been collected from Japanese plants, milling companies and research institutes. The proposed master curves of the creep rupture data is described using the following Larson-Miller parameter:

$$
L M P=(T+273.15)\left(C+\log t_{r}\right)=a_{0}+a_{1} \log \sigma+a_{2}(\log \sigma)^{2}+a_{3} \sigma
$$

where $T$ is the temperature in ${ }^{\circ} \mathrm{C}, t_{r}$ is the time to rupture in hours, $\sigma$ is the stress in MPa and $C, a_{0}$, $a_{1}, a_{2}$ and $a_{3}$ are the constants. The Larson-Miller constants for P91 plate steel and welded joints are summarised in Table 1 [16],[17].

The creep rupture curves for the $\mathrm{BM}$ and welded joints at $650^{\circ} \mathrm{C}$ are plotted in Figure 6 , where the mean line and 99\% lower limit line for the BM and welded joints are shown in solid and dashed lines, respectively. In addition, the rupture data for the large and small SENT specimens are plotted for comparison. As seen in Figure 6, the rupture data for large SENT specimens are just above the mean line of the welded joints, not the BM. The rupture data for small SENT specimen is located between $99 \%$ lower limit and the mean line of the welded joints. In this study, the initial crack length $\left(a_{i}=2 \mathrm{~mm}\right)$ of SENT specimens is quite shallow, which means that $a_{i} / W$ for large and small SENT specimens are 0.033 and 0.066 , respectively. Therefore, it can be suggested that when the initial crack/defect in components is quite shallow, such as the specimens tested in this study, a creep rupture curve for welded joints can be used to estimate the rupture life of the component using the net section stress. However, more experimental analysis is needed to validate the effect of initial crack/defect on the creep rupture life.

Compared with the creep rupture curve of the BM, the rupture time of the SENT specimens are much shorter than the $99 \%$ lower limit line of the master curve. As for large SENT2 specimen, the weld depth is $10 \mathrm{~mm}$ in $60 \mathrm{~mm}$ width (weld depth/specimen width of 1/6), which means that more than $80 \%$ of the net section is dominated by the BM. Nevertheless, the rupture life is close to that of the round bar tests of the welded joints, not that of the BM. Therefore, it can be said that when the initial defect/crack is located in the HAZ region in a welded P91 components, the calculation of the rupture life using the creep rupture data of the BM overestimates the component's lifetime.

Table 1: Larson-Miller constants for: (a) P91 BM [16], and (b) P91 welded joints [17]

(a)

\begin{tabular}{|l|c|c|}
\hline & High stress regime & Low stress Regime \\
\hline$C$ & 31.5907 & 20.6583 \\
\hline
\end{tabular}




\begin{tabular}{|l|c|c|}
\hline$a_{0}$ & 21,1885 & $23,067.7$ \\
\hline$a_{1}$ & $17,434.5$ & $3,744.7$ \\
\hline$a_{2}$ & $-6,076.1$ & $-2,144.9$ \\
\hline$a_{3}$ & 0 & 0 \\
\hline
\end{tabular}

(b)

\begin{tabular}{|l|c|c|}
\hline & High stress regime & Low stress Regime \\
\hline$C$ & 34.7767 & 22.5811 \\
\hline$a_{0}$ & $37,455.9$ & $31,306.0$ \\
\hline$a_{1}$ & $4,240.8$ & $-4,166.8$ \\
\hline$a_{2}$ & -2986.1 & 0 \\
\hline$a_{3}$ & 0 & -0.1728 \\
\hline
\end{tabular}

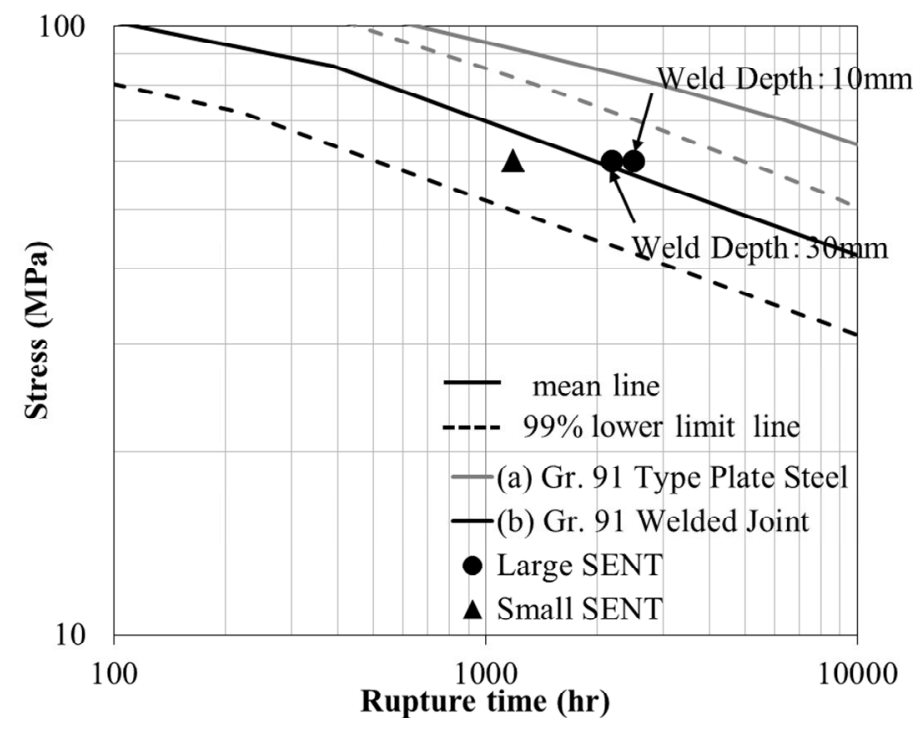

Figure 6: Comparison of the rupture data between P91 SENT specimens and uniaxial tests at $650^{\circ} \mathrm{C}$

\subsection{Crack path analysis}

The observed crack paths in the SENT specimens tested in previous study by Yatomi et al. [10] show that the creep crack initiates from the EDM notch in the HAZ region, it propagates along the semi-elliptical shape of the weld path and follows the Type IV region until the sample ruptures under uniaxial creep loading conditions. The crack path and rupture behaviour of the large SENT1 specimen has been shown in Figure 7 as an example of the crack growth behaviour in the examined specimens. As seen in Figure 7, the crack initially propagated at an angle normal to the loading direction (i.e. along the initial EDM starter crack), but is subsequently deviated towards an angle parallel to the loading direction (see the blue dashed line in Figure 7) until the final failure eventually occurred due to creep rupture at the end of the test. A similar crack path was also seen in large 
SENT2 and small SENT specimens. The observed crack path indicates that some errors will be encountered in the correlation of the CCG rate, $d a / d t$, with the $C^{*}$ parameter if the crack growth direction is not carefully considered in the analysis. Therefore, finite element modelling needs to be performed in order to accurately predict the crack path and its subsequent effect on the rupture life of welded components with Type IV cracks.

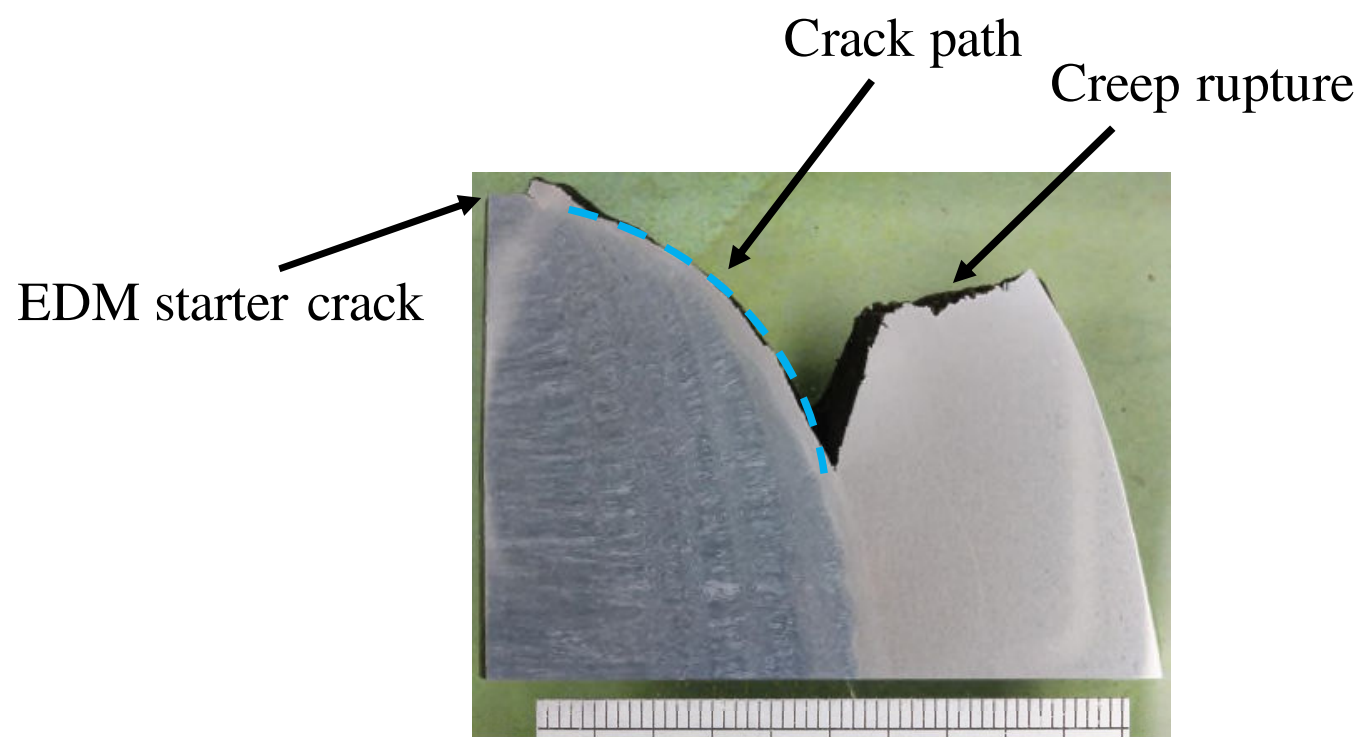

Figure 7: Post-mortem analysis of the crack path in SENT1 specimen (taken from [10])

\section{Finite Element Modelling of SENT Weld Specimens}

In this section, finite element analysis were conducted on the examined welded geometries to investigate the fracture parameters behaviour of the large-scale SENT specimens. Finite element simulations were carried out in conjunction with damage modelling on the large-scale SENT welded geometries to predict the failure times and the crack path in the examined test specimens. The prediction results have been validated through comparison with the experiment data presented in Section 2. The model set-up, material properties, boundary conditions, mesh structure and finite element prediction results are presented and discussed below.

\subsection{Specimen geometry and material properties}

The large SENT1 and SENT2 specimens were modelled in ABAQUS finite element software package to predict the creep crack path and the failure time in such welded components. Due to the symmetrical shape of the welded plate, only half of the geometry was modelled as shown in Figure 8. A symmetrical boundary condition was applied to the left edge and the distributed force was applied to the right edge which represents the load bearing end of the specimen. The welded area, the HAZ area and the BM area were divided in relation to the actual test specimens. The HAZ area was located between the WM and the BM areas with the width of the HAZ region set to $2 \mathrm{~mm}$. 


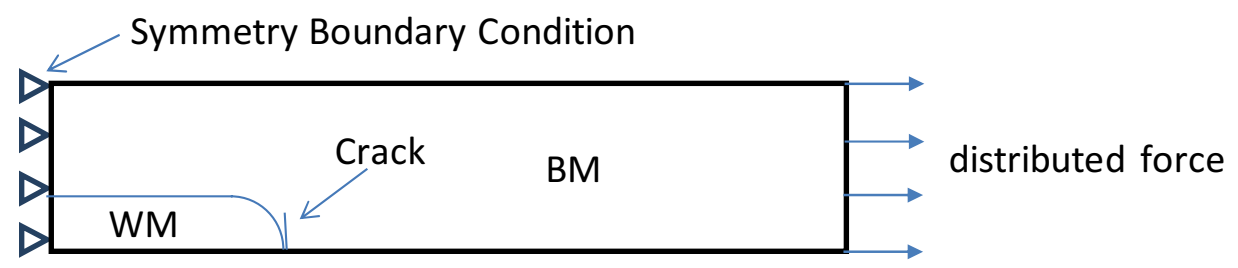

Figure 8: The boundary conditions applied in finite element simulations on the SENT welded geometries

For a power-law creeping material under steady state conditions, the creep strain rate, $\dot{\varepsilon}$, can be correlated with the equivalent stress, $\sigma$, using [11];

$$
\dot{\varepsilon}=A \sigma^{n}
$$

where $n$ and $A$ are the uniaxial creep constants which depend on the material and the testing temperature. The uniaxial creep properties obtained from Equation (2), which is known as Norton's law, are often used in damage analysis of materials subjected to creep loading conditions. The elastic Young's modulus, $E$, and yield stress, $\sigma_{y}$, values employed in the finite element analysis for the WM, HAZ and BM regions are shown in Table 2. Also included in this table are the uniaxial creep properties for the WM, HAZ and BM where $n$ and $A$ are the power-law constants derived from Equation (2) and $\varepsilon_{f}$ is the uniaxial creep strain at failure, which is often referred to as creep ductility. In this table, the mean creep properties are presented which describe the long-term behaviour of P91 steel. The long-term creep properties were employed in finite element simulations to simulate the welded component's response under realistic operational loading conditions [18]. In the case of failure strain in the HAZ region which is difficult to measure, a lower failure ductility was adopted which contributed to a faster development of the crack in that region [19]. In comparison with the $\mathrm{WM} / \mathrm{BM}$ region which effectively constrain the HAZ region, the strain rate for the HAZ material is larger allowing a faster rate of Type IV damage development in the interface region.

Table 2: Mechanical and creep properties of P91 welded joints at $650{ }^{\circ} \mathrm{C}$

\begin{tabular}{|c|c|c|c|c|c|}
\hline & $E(\mathrm{GPa})$ & $\sigma_{\mathrm{y}}(\mathrm{MPa})$ & $A$ & $n$ & $\varepsilon_{f}$ \\
\hline WM & 140 & 188 & $1.0 \times 10^{-22}$ & 7.5 & 0.27 \\
\hline HAZ & 140 & 180 & $9.0 \times 10^{-22}$ & 7.5 & 0.01 \\
\hline BM & 140 & 173 & $3.0 \times 10^{-22}$ & 7.5 & 0.37 \\
\hline
\end{tabular}

\subsection{Damage modelling approach}

During the creep analysis, the rupture strain and stress triaxiality may be considered as the most influential factors. In the present study, a damage modelling approach was implemented in which the load carrying capacity of the elements continuously decreased as the accumulated damage value, $\omega$, increased using the following relationship:

$$
E=E_{0}(1-\omega)
$$

where $E$ is the Young's modulus and $E_{0}$ is the modulus of elasticity for an undamaged material. Knowing that the value of the damage parameter varies between zero and unity, this equation shows that the Young's modules (i.e. stiffness) of an element varies between $E_{0}$ (for un-damage material) 
and zero (for fully damage material). In this work, the creep damage was defined as the integral of the creep strain rate to the multiaxial creep ductility (i.e. creep strain at failure) ratio at the damage accumulation rate given by,

$$
\dot{\omega}=\frac{\dot{\varepsilon}^{c}}{\varepsilon_{f}^{*}}
$$

where $\varepsilon_{f}^{*}$ is the multiaxial creep ductility and $\dot{\varepsilon}^{c}$ is the creep strain rate. The value of $\varepsilon_{f}^{*}$ for a range of stress states may be estimated from the uniaxial failure strain over different test times. The model identifies uniaxial ductility, $\varepsilon_{f}$, as the parameter with the greatest influence in the crack path and CCG rates as this property directly influences the rate of damage and the level of multiaxial ductility derived from the multiaxial strain factor $(\mathrm{MSF})$, (i.e. $\left.\varepsilon_{f}^{*}=M S F \times \varepsilon_{f}\right)$ in the implemented model [20]. The MSF value can be estimated using an appropriate model, such as Cocks and Ashby void growth and coalescence model [20], which is shown in Equation (5) and was implemented in this study. As seen in this equation, the Cocks and Ashby model depends on the stress triaxiality, which is the ratio between the mean (hydrostatic) stress and the equivalent (von Mises) stress, $\sigma_{m} / \sigma_{e}$, and $n$.

$$
M S F=\frac{\varepsilon_{f}^{*}}{\varepsilon_{f}}=\sinh \left[\frac{2}{3}\left(\frac{n-0.5}{n+0.5}\right)\right] / \sinh \left[2\left(\frac{n-0.5}{n+0.5}\right) \frac{\sigma_{m}}{\sigma_{e}}\right] .
$$

The total damage at a given time, $t$, is then taken as the integral of the damage rate up to that time, which can be described by:

$$
\omega=\int_{0}^{t} \dot{\omega} d t
$$

Similar to Equation (3), a damage index can also be defined to degrade an element's stress using;

$$
\sigma=(1-D) \bar{\sigma}
$$

where $\sigma$ is the stress at any element integration point after damage accumulation, $D$ is the damage parameter and $\bar{\sigma}$ is the effective stress tensor in the undamaged material. According to this equation, a fully damaged element loses its load carrying capacity when the damage parameter reaches unity. The progressive change in the load carrying capacity of an element during the damage accumulation process $(0 \leq D \leq 1)$ is schematically shown in terms of stress-strain response in Figure 9. In this study the value of $D$ was directly correlated to the value of $\omega$.

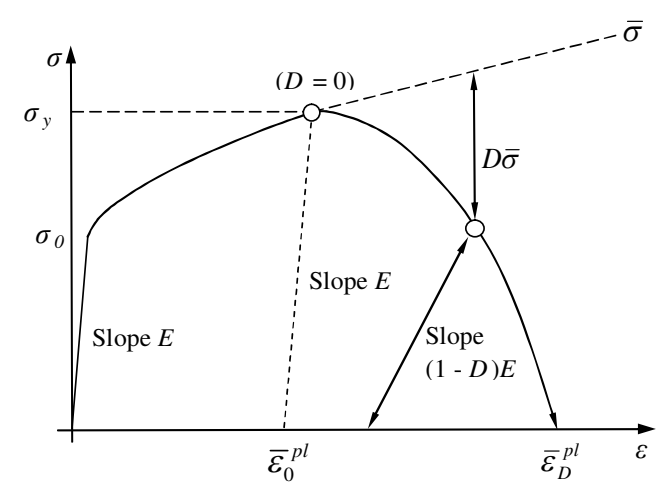


Figure 9: The change in the load carrying capacity of an element during damage accumulation

\subsection{Mesh design and sensitivity analysis}

A set of preliminary finite element analyses were carried out to explore the stress discontinuity around the HAZ region where the crack starts to propagate. Two high density mesh structures, with structured elements (see Figure 10(a)) and free elements (see Figure 10(b)), were designed and assigned to the SENT weld geometry to examine the sensitivity of the stress distribution to the mesh design. As seen in Figure 10, a fine mesh was assigned to the HAZ region and the elements were coarsened away from the crack growth region. Following the sensitivity analysis on the mesh size from previous studies [21]-[25], a fine element size of $0.001 \mathrm{~mm}$ was assigned to the HAZ region. It has been shown in previous studies [21]-[25] that the selected element size in the present study is the smallest value using which accurate crack growth simulation results with reasonable computational times can be achieved. It is evident in the stress distribution contours plots in Figure 10 that the mesh structure can influence the local stress values in the finite element simulations while the global stress distribution maps are similar to each other.

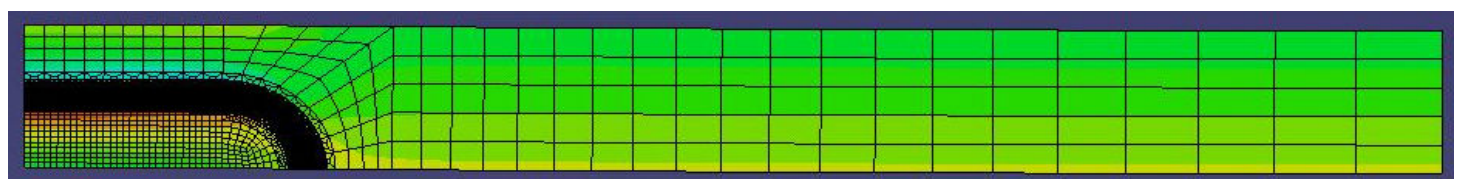

(a)

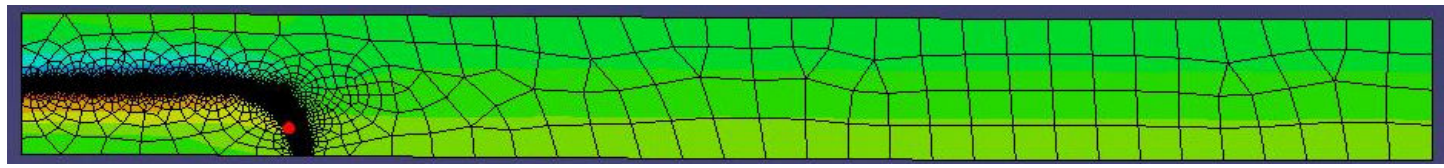

(b)

Figure 10: SENT finite element model with: (a) structured mesh, and (b) free mesh

The local stress distribution contour plots in the vicinity of the HAZ region, which is the area of interest for crack initiation and propagation analysis, are presented in Figure 11(a) and Figure 11(b) for simulation results obtained from the structured and free mesh, respectively. By comparing the structured mesh and free mesh results, it can be seen that the structured mesh gives a smooth stress distribution prediction close to the interface between the BM and WM, hence it is a more suitable mesh strategy for simulating the crack path and CCG prediction in the SENT weld samples. It is worth noting that because of the numerical integration near the interface, the continuity of solution is dependent on the arrangement of the elements around the interface. Therefore, an appropriate mesh design must be assigned to the model in order to predict the crack path accurately.
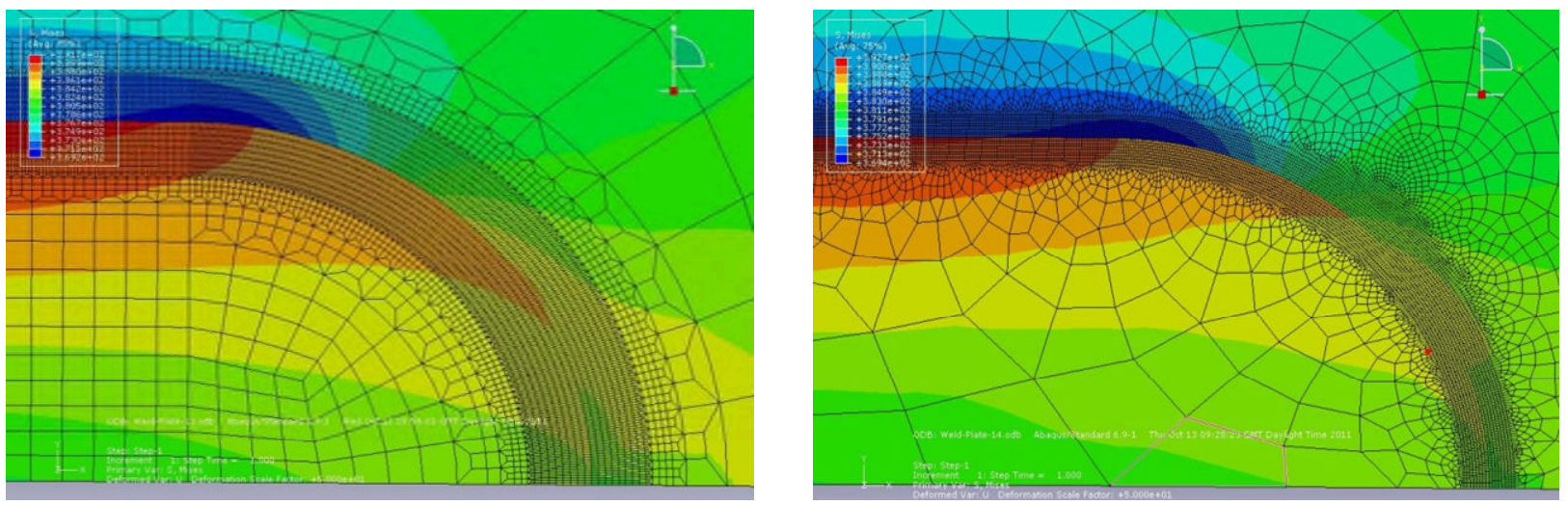
(a)

Figure 11: Local stress distribution around the HAZ region using: (a) structured mesh, and (b) free mesh

\subsection{Crack path predictions under simple loading conditions}

After selecting the optimum mesh design, preliminary finite element simulations were performed to predict the crack path in SENT welded geometries using a simple loading condition. In these simulations, a constant displacement was applied on the edge of the SENT geometry which was gradually increased during the simulation time. In the crack growth simulations, damage analysis was carried out according to the model presented in Section 3.2 and the element deletion technique was used to advance the crack. In this approach, once the damage parameter reaches the critical value of unity, the element's stiffness is to zero and the crack propagation is simulated by deleting the damaged element. Figure 12 shows the crack growth simulation in the large SENT welded specimen with the depth of $30 \mathrm{~mm}$ (SENT1). As seen in Figure 12(a), at the beginning of the crack growth simulation process the crack moves close to the interface of the WM for around $12 \mathrm{~mm}$ and then it starts to deviate from the HAZ region. It can be seen in Figure 12(b) that after crack initiation, it propagates along a nearly straight direction zig-zagging around a line normal to the loading direction. The next step in the cracking behaviour in Figure 12(c) shows that the crack propagates along a relatively stable path and direction, whereas in Figure 12(d) the crack changes its direction several times around a line which is perpendicular to the maximum principal stress direction.

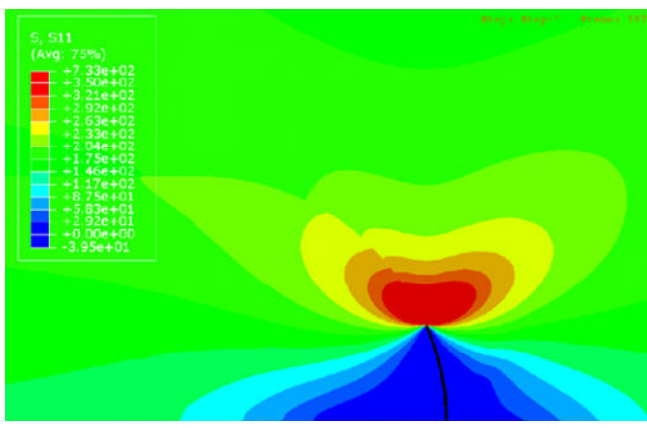

(a)

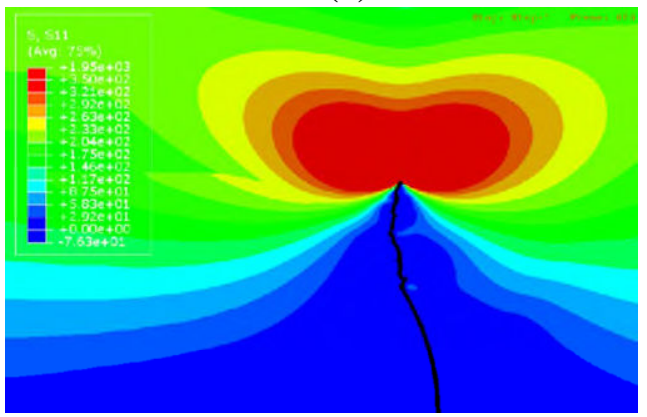

(c)

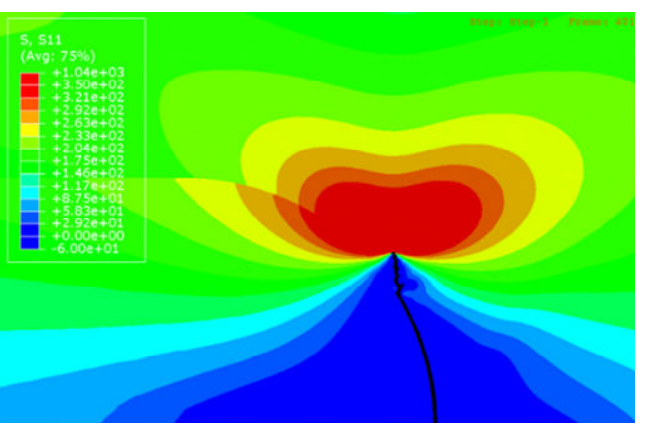

(b)

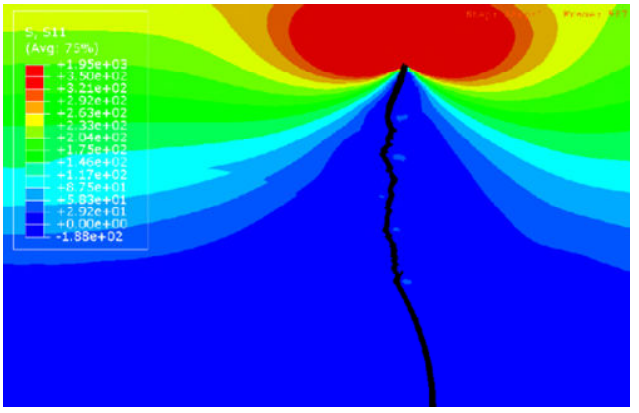

(d)

Figure 12: Finite element crack growth simulation results on SENT1 specimen geometry at four different stages of the simulation process

The crack path analysis results on the large SENT specimen with $10 \mathrm{~mm}$ weld depth (SENT2) is shown in Figure 13. As it is seen in Figure 13(a), the crack moves close to the interface of the weld for around $12 \mathrm{~mm}$ and then it starts to deviate from the round shape of the weld region. In Figure 13(b) the crack grows by changing its direction and extending through the plate width. In Figure 13(c) the crack follows a zig-zag path and in Figure 13(d) the crack continues to change its direction several times while in the macro scale it follows a straight line which is normal to the loading 
direction. The crack path simulation results on SENT1 and SENT2 specimens show that the examined weld geometries have tendency towards net rupture once the crack deviates from the HAZ region. In other words, after the initial stage of crack growth along the HAZ region, the crack may deviate from weld region and penetrate into the BM which eventually leads to the global failure of the weld geometry.

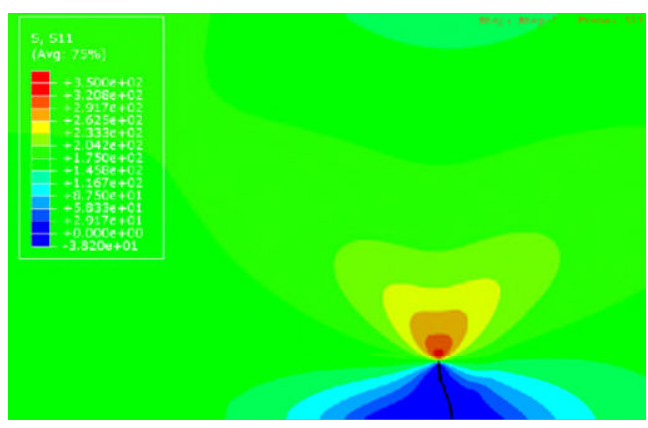

(a)

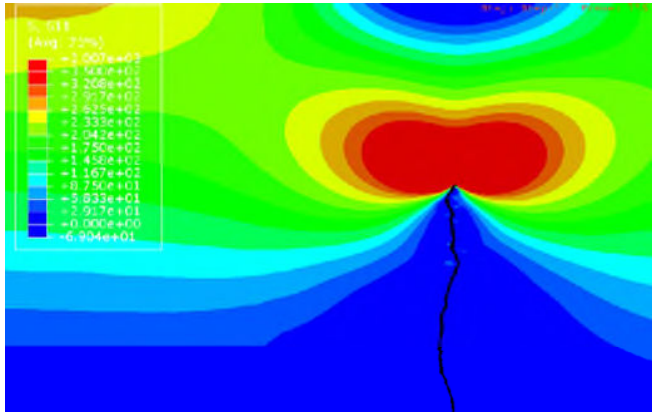

(c)

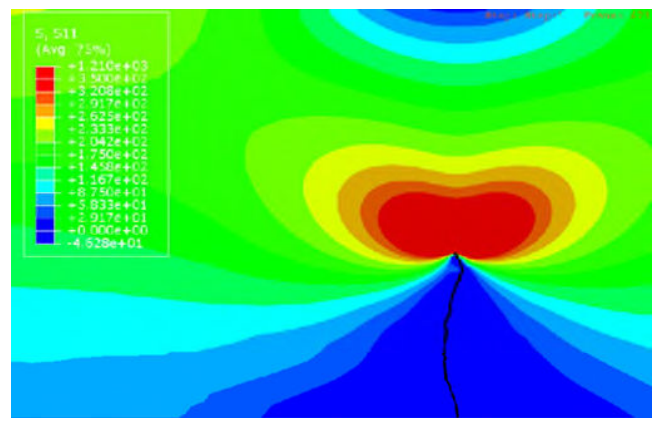

(b)

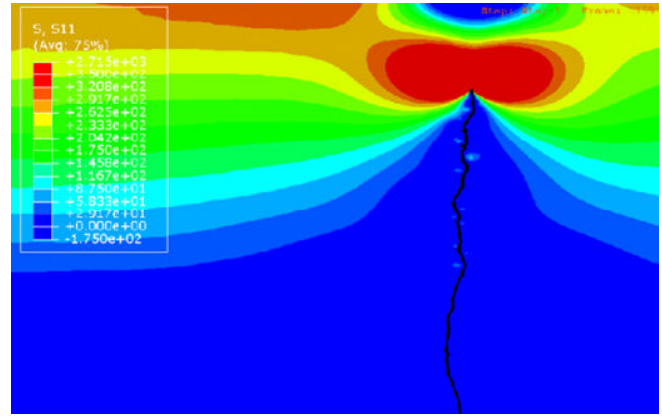

(d)

Figure 13: Finite element crack growth simulation results on SENT2 specimen geometry at four different stages of the simulation process

\subsection{Finite element simulation results on SENT weld specimens}

After examination of the crack path under simple loading conditions (i.e. displacement), a distributed force was applied on the edge of the SENT geometry replicating the boundary conditions shown in Figure 8. The predicted crack path from these simulations on SENT1 and SENT2 geometries are presented in Figure 14(a) and Figure 14(b), respectively. Comparing the crack path analysis under a constant displacement shown in Figure 12 and Figure 13 with those of predicted using distributed forces in Figure 14 it can be seen that the crack path and propagation direction is clearly dependent on the mode of applied loading condition. Figure 14 shows that when a distributed force is applied on the edge of the SENT1 and SENT2 weld geometries, a longer crack growth along the HAZ region is predicted compared to the constant displacement simulation results where the crack deviated from the HAZ region at the early stages of the simulation. This is thought to be due to bending upon crack propagation which occurs using distributed forces compared to a constant displacement boundary condition. These numerical analyses show that the boundary condition can directly influence the predicted crack path in tapered weld geometries with a curved HAZ region. It is also worth noting that the assigned creep ductility to the HAZ region has a significant impact on the predicted CCG rate and the crack path, therefore the value which has been reported in Table 2 (creep ductility of 0.01 for HAZ region) was obtained through an iterative process and by minimising the error between prediction results and the experimental data. A proposed methodology for accurate numerical analysis of the crack path and CCG rates in complicated weld geometries with Type IV cracks is illustrated in Figure 15. 

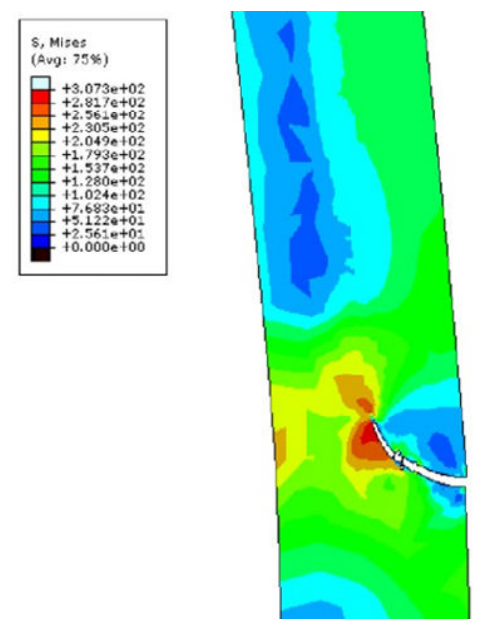

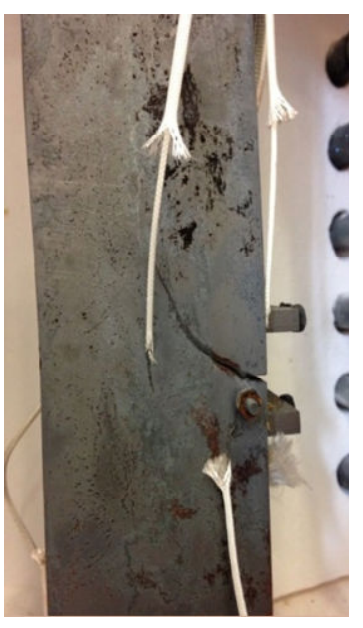

(a)
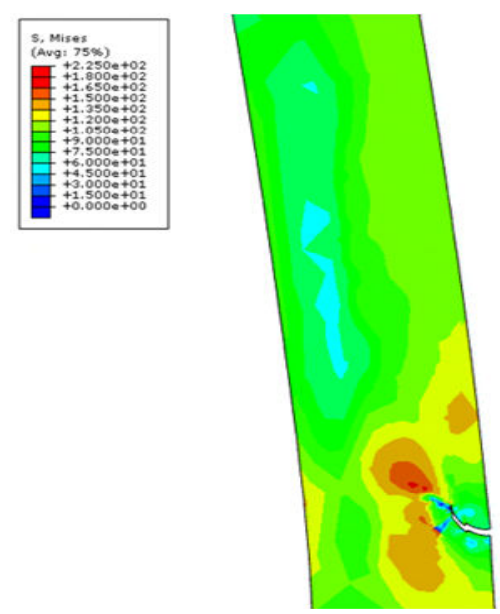

(b)

Figure 14: (a) Comparison of finite element crack growth simulation results with experimental observation for SENT1 specimen, (b) numerical prediction of crack propagation results in large SENT2 specimen

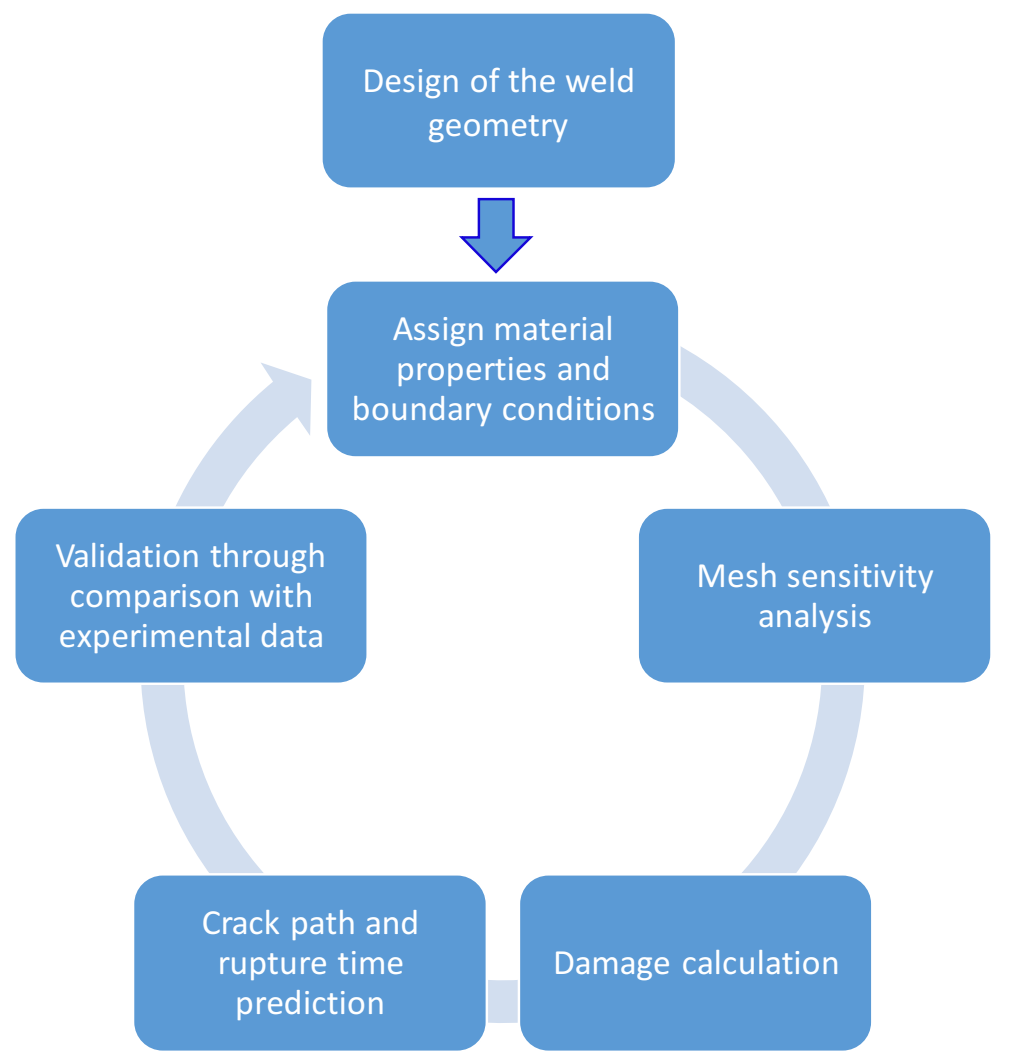

Figure 15: A flowchart of the finite element analysis procedure

The numerical CCG prediction results for the large SENT1 specimen is shown in Figure 14. It can be seen in Figure 14(a) that the predicted crack growth behaviour compares well with the experimental observations. The same trend and a similar crack path has been found from the finite element simulations on the large SENT2 specimen as shown in Figure 14(b). The numerical predictions of the displacement in the middle and the top and bottom of the SENT1 and SENT2 specimens are shown in Figure 16(a) and Figure 16(b), respectively. The comparison of the predicted axial displacement 
in the middle of the large SENT1 specimen, shown in Figure 16(a), with the experimental data for this specimen (see Figure 4(a)) shows that the final displacement of $1.7 \mathrm{~mm}$ predicted by the finite element simulation is in good agreement with the $2.4 \mathrm{~mm}$ axial displacement which was experimentally measured in the large SENT1 specimen. Moreover, the level of displacement before the rapid acceleration starts to occur compares well between the numerical predictions and the experimental data, though an earlier increase in axial displacement is predicted using finite element simulation for large SENT1 specimen.

The total rupture times measured and predicted for the large SENT1 and SENT2 specimens are summarised in Table 3. It can be seen in this table that there is a very good agreement between the numerically predicted and experimentally measured rupture times in both samples with the finite element simulations predicting values within maximum $10 \%$ of the experimental rupture times. This indicates that for the purpose of comparing numerical predictions with the limited experimental results, using the material properties presented in Table 2 leads to an acceptable prediction of failure times and axial displacements in large SENT1 and SENT2 specimens. A more detailed sensitivity analysis on the creep power-law constants will be carried out in future work. Moreover, further analyses will be carried out in the future to provide a reliable estimation of the instantaneous crack length for non-straight crack paths in order to increase the accuracy of the CCG rate correlation with $C^{*}$ parameter for such welded geometries with a semi-elliptical HAZ region.

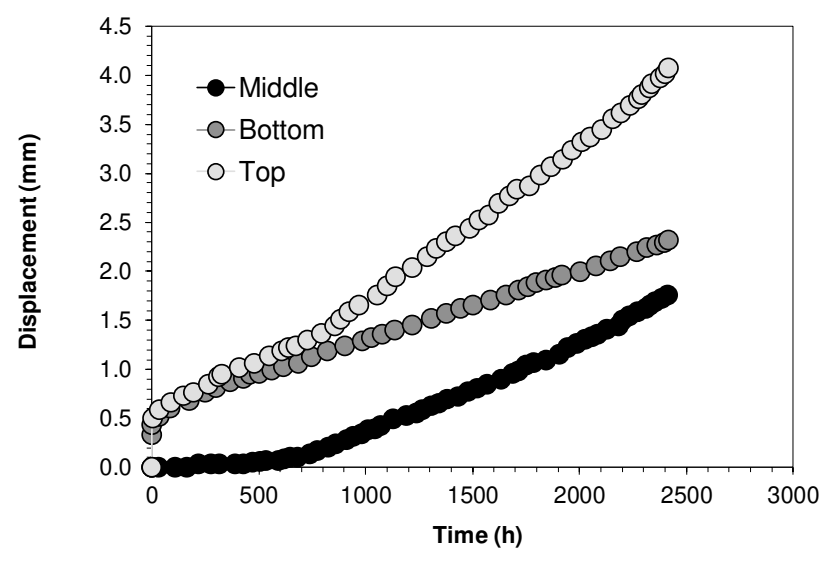

(a)

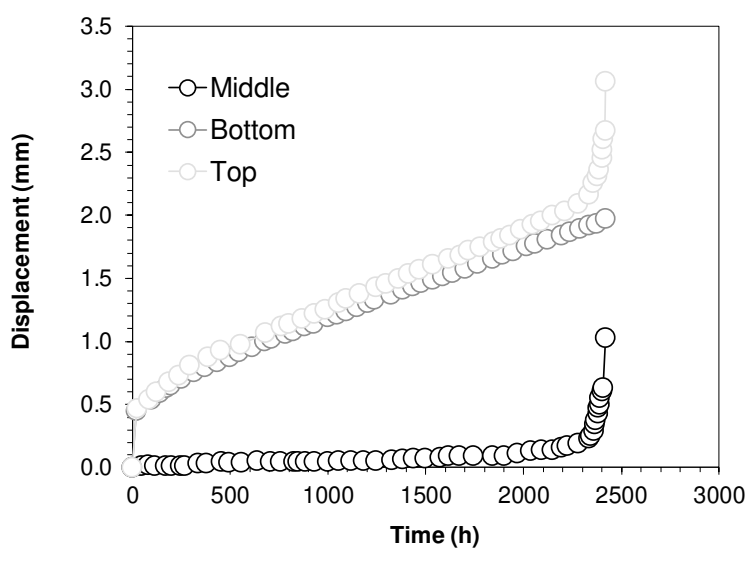

(b)

Figure 16: Numerical prediction of the axial displacement against time for (a) SENT1, and (b) SENT2 specimen

Table 3: Comparison between predicted and experimental rupture times for large SENT specimens

\begin{tabular}{|l|c|c|}
\hline & $\begin{array}{c}\text { Experimental rupture } \\
\text { time } \\
\text { (hours) }\end{array}$ & $\begin{array}{c}\text { Predicted rupture } \\
\text { time }\end{array}$ \\
(hours)
\end{tabular}




\begin{tabular}{|l|l|r} 
Large SENT2 & 2,505 & 2420
\end{tabular}

\section{Conclusions}

Creep tests were conducted on P91 SENT specimens with a semi-elliptical weld geometry. Two large-scale specimens and one small-scale sample were tested at $650{ }^{\circ} \mathrm{C}$ and the obtained results were compared with those of available in the literature. Furthermore, finite element analyses were performed to predict the crack path, axial displacement and rupture time in large-scale SENT weld specimens. The results show that although the crack propagation starts with an angle normal to the loading direction, the crack deviates towards an angle parallel to the loading direction and follows the Type IV region with the final failure occurring due to rupture of the uncracked ligament at the end of the test. This behaviour was observed both in large-scale and small-scale SENT specimens. The finite element simulation results have shown that the implemented creep damage model accurately predicts the crack path, axial displacement and rupture time in large SENT weld specimens. These satisfactory results were obtained by assigning a lower creep ductility to the HAZ region at the interface between the $\mathrm{WM}$ and $\mathrm{BM}$. This suggests that the proposed modelling approach and material properties can be employed to predict the crack growth rates in real-life welded components with Type IV cracks made of P91 steel. Finally, the results suggest that the creep damage in the Type IV crack regions occur at a faster rate than the WM/BM region and this leads to crack deviation towards an angle parallel to the loading direction and eventually failure due to creep rupture.

\section{References}

[1] Bell, K., Elevated temperature midlife weldment cracking (Type IV)-A review. TWI Report. 1997.

[2] Ellis, F. V., Review of Type IV cracking in piping welds. ASME-PVP 380. 1998.

[3] Hongo, H., Tabuchi, M. and Watanabe, T., Type IV creep damage behavior in Gr. 91 steel welded joints. Metallurgical and Materials Transactions A. 2012 Apr 1;43(4):1163-73.

[4] Besson, J,. Leclercq, S., Gaffard, V. and Gourgues-Lorenzon, A. F., Analysis of creep lifetime of a ASME Grade 91 welded pipe. Engineering Fracture Mechanics. 2009 Jul 1;76(10):146073.

[5] Dogan, B. and Petrovski, B., Creep crack growth of high temperature weldments, International Journal of Pressure Vessels and Piping, 2001, 78(11-12), pp. 795-805.

[6] Tan, M., Célard, N. J. C., Nikbin, K. M and Webster, G. A., Comparison of Creep Crack Initiation and Growth in Four Steels Tested in HIDA, International Journal of Pressure Vessels and Piping, 2001, 78(12), pp. 737-747.

[7] Hamata, N. L. and Shibli, I. A., Creep crack growth of seam-welded P22 and P91 pipes with artificial defects. Part I. Experimental study and post-test metallography. International journal of pressure vessels and piping. 2001 Nov 12;78(11-12):819-26.

[8] Hamata, N. L. and Shibli, I. A., Creep crack growth of seam-welded P22 and P91 pipes with artificial defects. Part II. Data analysis. International journal of pressure vessels and piping. 2001 Nov 12;78(11-12):827-35. 
[9] Hyde, T. H., Saber, M. and Sun., W., Testing and modelling of creep crack growth in compact tension specimens from a P91 weld at $650^{\circ} \mathrm{C}$, Engineering fracture mechanics, 2010, 77(15), pp. 2946.

[10] Yatomi, M., Mehmanparast A., Maleki, S., Nikbin KM. The Weld Depth and Angle Acuity Effects on the Crack Growth Behaviour of P91 Feature Test Specimens. In ASME 2014 Pressure Vessels and Piping Conference 2014 Jul 20. American Society of Mechanical Engineers Digital Collection.

[11] Norton, F. H., The creep of steel at high temperatures. McGraw-Hill Book Company, Incorporated; 1929.

[12] Webster, G. A. and Ainsworth, R. A., High Temperature Component Life Assessment, 1st ed, 1994, London: Chapman and Hall.

[13] ASTM E1457-15, Standard Test Method for Measurement of Creep Crack Growth Times in Metals, ASTM International, West Conshohocken, PA, 2015

[14] Zhou, H., Biglari, F., Mehmanparast, A., Davies, C. M. and Nikbin, K. M., Evaluation of Fracture Mechanics Parameters for a Range of Weldment Geometries with Different Mismatch Ratios, Engineering Fracture Mechanics, 2014, 124-125, pp30-51.

[15] Tabuchi M, Hongo H, Sugiura R, Yokobori Jr AT, Yatomi M, Kobayashi K. Evaluation of damage and fracture of high $\mathrm{Cr}$ steel welds at elevated temperatures. Strength, Fracture and Complexity. 2015 Jan 1;9(1):31-41.

[16] Kimura, K.. and Yaguchi, M., Re-evaluation of long-term creep strength of base metal of ASME grade 91 type steel. In ASME 2016 pressure vessels and piping conference 2016. American Society of Mechanical Engineers Digital Collection.

[17] Yaguchi, M., Nakamura, K. and Nakahashi, S., Re-evaluation of long-term creep strength of welded joint of ASME Grade 91 type steel. In ASME 2016 Pressure Vessels and Piping Conference 2016. American Society of Mechanical Engineers Digital Collection.

[18] Mehmanparast, A., Davies, C. M., Webster, G. A. and Nikbin, K. M., Creep crack growth rate predictions in $316 \mathrm{H}$ steel using stress dependent creep ductility. Materials at High Temperatures. 2014 Jan 1;31(1):84-94.

[19] Maleki, S,. Mehmanparast, A. and Nikbin KM. Creep Crack Growth Prediction of Very Long Term P91 Steel Using Extrapolated Short-Term Uniaxial Creep Data. In ASME 2013 Pressure Vessels and Piping Conference 2013. American Society of Mechanical Engineers Digital Collection.

[20] Cocks, A. C. F. and Ashby, M. F., Intergranular Fracture During Power-Law Creep under Multi-Axial Stress, Metal Science, 1980, 14, pp. 395-402.

[21] Jacob, A. and Mehmanparast, A., Sensitivity analysis of material microstructure effects on predicted crack paths using finite element simulations. Journal of Multiscale Modelling, 2016, 7(02), p.1650003.

[22] Biglari, F. and Nikbin, K.M., Environmental creep intergranular damage and multisite crack evolution model for engineering alloys. Computational materials science, 2014, 84, pp.267277.

[23] Mehmanparast, A. and Nikbin, K., The importance of micro-crack evolution under oxidation/creep conditions in component failure life predictions. In Key Engineering Materials, 2015, Vol 627, pp. 209-212, Trans Tech Publications Ltd. 
[24] Mehmanparast, A., Prediction of creep crack growth behaviour in 316H stainless steel for a range of specimen geometries. International Journal of Pressure Vessels and Piping, 2014, 120, pp.55-65.

[25] Quintero, H. and Mehmanparast, A., Prediction of creep crack initiation behaviour in 316H stainless steel using stress dependent creep ductility. International Journal of Solids and Structures, 2016, 97, pp.101-115. 